\title{
FORÇA DE TRAÇÃO E VOLUME DE SOLO MOBILIZADO POR HASTE SULCADORA EM SEMEADURA DIRETA SOBRE CAMPO NATIVO, EM FUNÇÃO DO TEOR DE ÁGUA NO SOLO, PROFUNDIDADE E VELOCIDADE DE OPERAÇÃ ${ }^{1}$
}

\author{
CARLA T. C. CEPIK ${ }^{2}$, CARLOS R. TREIN ${ }^{3}$, RENATO LEVIEN $^{3}$
}

RESUMO: A semeadura direta é um sistema de manejo eficiente em termos de conservação do solo e da água, economia de energia e capacidade operacional dos conjuntos mecanizados. No entanto, em áreas onde existem pecuária e produção de grãos, ou onde o solo é trafegado e trabalhado em condições inadequadas, pode ocorrer compactação do solo nas camadas superficiais. Mesmo compactadas, essas camadas não necessitariam ser descompactadas ou revolvidas, se boa germinação e desenvolvimento da cultura fossem alcançados apenas com a mobilização efetuada pelos sulcadores da semeadora. Os objetivos deste estudo foram determinar a força de tração demandada e o volume de solo mobilizado pelas hastes sulcadoras de adubo, além da patinagem do trator, em diferentes estados de consistência de um Argissolo, em semeadura direta sobre campo nativo dessecado. Houve aumento na demanda de tração com o aumento da profundidade de atuação da haste, e sua magnitude dependeu do estado de consistência do solo. $\mathrm{O}$ aumento da velocidade não influenciou na força de tração na haste em solos seco e úmido, porém, na condição de friabilidade, essa foi maior. O volume de solo mobilizado pelo sulcador foi maior em solo seco e a $12 \mathrm{~cm}$ de profundidade. Nos estados de consistência seco e friável e na maior profundidade testada, verificou-se a necessidade de acionamento da TDA do trator para obtenção de níveis aceitáveis de patinagem.

PALAVRAS-CHAVE: mobilização do solo, patinagem, semeadora-adubadora de precisão.

\section{DRAFT AND SOIL LOOSENING BY KNIFE TYPE COULTER RELATED TO SOIL MOISTURE AND PLANTER'S WORKING SPEED AND DEPTH}

\begin{abstract}
Direct drilling or no tillage systems are among the most successful agricultural alternatives regarding soil and water conservation, energy economy and operational capacity of machinery. Some areas where cattle raising and grain production share the same grounds, or where soils are trafficked in moist conditions they may show compaction of the upper layers. Compacted soil areas may not need to be chiseled or plowed, if seed germination and good growing standards are reached by the initial soil conditioning solely by planter's coulters. The specific aims of the present work are to determine the knowledge of coulter draft requirements and the amount of displaced soil and tractor slippage on a Paleudult soil at different soil moisture condition, in direct planting on natural pastures chemically killed. Draft requirements increased with an increase in working depth. The increase of the ground speed had no effect on draft when soil was dry or moist; it increased however, on friable soil. Soil displacement was always higher with dry soil and at $12 \mathrm{~cm}$ working depth. When soil was friable or dry, the front wheels traction was needed to keep tractor slippage within acceptable levels.
\end{abstract}

KEYWORDS: soil mobilization, tire slippage, planter.

\footnotetext{
${ }^{1}$ Realizado com apoio da CAPES e CNPq-PRONEX/Solos.

${ }^{2}$ Eng $^{\mathrm{a}}$ Agrícola, Doutoranda em Ciência do Solo, FA/UFRGS, Porto Alegre - RS, carlacepik@bol.com.br

${ }^{3}$ Professor Adjunto, Departamento de Solos, FA/UFRGS, Porto Alegre - RS.

Recebido pelo Conselho Editorial em: 5-9-2003

Aprovado pelo Conselho Editorial em: 20-10-2004
} 


\section{INTRODUÇÃO}

As preocupações em relação à eficiência dos sistemas de preparo do solo são crescentes na agricultura em todo o mundo. Para aumentar a eficiência no processo produtivo, novos sistemas de preparo do solo vêm sendo propostos visando a minimizar e/ou a eliminar as perdas de solo por erosão, características em preparos convencionais de solo.

Dentre as alternativas que estão sendo utilizadas no País desde a década de 1980, destaca-se a técnica conhecida por semeadura direta, atualmente bastante difundida entre produtores rurais. No entanto, em áreas onde esse sistema está implantado há mais tempo ou onde existe a integração lavoura-pecuária, pode ocorrer compactação superficial do solo. Essa compactação é devida, fundamentalmente, ao tráfego de máquinas em solos com elevado teor de água ou sob utilização inadequada da técnica de semeadura direta (SOANE \& OUWERKERK, 1994). Para resolver o problema causado pela compactação da camada superficial do solo, muitos agricultores retornam aos métodos de preparo tradicionais, com revolvimento parcial ou total do solo.

A compactação do solo é causada pelo rearranjo de suas partículas sólidas. O teor de água no solo, no momento em que ocorre a compactação é fator determinante da sua intensidade. Qualquer que seja a operação agrícola, caso seja efetuada no solo com teores de água inadequados, implicará deterioração de seus atributos físicos (BOENI, 2000).

Muitas áreas afetadas por compactação superficial não necessitariam ser descompactadas ou revolvidas, caso as semeadoras-adubadoras fossem melhor utilizadas, posicionando corretamente a semente de forma a proporcionar uma adequada germinação e emergência, mesmo em solos com diferentes teores de água. A definição do teor de água no solo, ideal para a execução das operações agrícolas, e a estimativa da deformação que ocorrerá quando as pressões a ele aplicadas excederem a sua capacidade de suporte de carga, são determinantes para evitar a sua compactação (SILVA, 1999).

Atualmente, na semeadura direta, tem-se por objetivo produzir sulcos satisfatórios com o uso de um mesmo tipo de sulcador, numa mesma configuração e regulagem, nas mais diversas condições de umidade e graus de consolidação do solo. É sabido, porém, que o solo se comporta diferentemente frente a essas condições. Sendo assim, é lógico depreender que as condições de abertura do sulco em que a semente deverá se desenvolver, serão diferentes em cada uma das situações e que ocorrerão diferenças na eficiência operacional do conjunto trator/semeadora-adubadora. Essas variações podem tornar o processo de semeadura economicamente inviável, devido a gastos energéticos elevados ou se a emergência não for satisfatória (CEPIK, 2002).

BERTOL et al. (1997) desenvolveram estudo relacionando diferentes tipos de sulcadores com as variáveis rugosidade e cobertura vegetal. Concluíram que é desejável utilizar sulcadores que proporcionem menor largura de sulco, evitando a ocorrência de possíveis invasoras e a competição por elas causada com a cultura estabelecida. Entre os sulcadores utilizados (disco duplo defasado, disco duplo e disco côncavo), o de disco côncavo foi o que mais reduziu a cobertura do solo, o que pode ser explicado pelo fato de o deslocamento dar-se em ângulo em relação à direção de trabalho, abrindo sulcos mais largos.

Segundo CASÃO JÚNIOR et al. (2000), para o emprego da semeadura direta em determinados locais, há necessidade de solucionar alguns problemas, tais como, compactação do solo, baixos teores de matéria orgânica, baixa fertilidade do solo, presença de plantas daninhas e excessivo consumo energético, em função de uma seleção inadequada das máquinas existentes no mercado. A adaptação das máquinas às realidades regionais é de suma importância para a eficiência da técnica.

CASÃO JÚNIOR et al. (1998) verificaram que os sulcadores do tipo facão providos com adequados ângulos de ataque nas hastes e nas ponteiras têm maior facilidade de penetração no solo e menor exigência de tração. Estudos conduzidos pelos mesmos autores revelaram que, numa mesma 
condição de solo e profundidade de semeadura, houve diferenças de até $50 \%$ entre sulcadores tipo facão comercialmente utilizados em semeadoras-adubadoras de precisão. Isso evita que as semeadoras equipadas com esse mecanismo dependam basicamente da transferência de peso da máquina para promover a penetração dos discos de corte dos resíduos e dos discos duplos (sulcadores para deposição das sementes) no solo. Outro fator de destaque é que esses promoveram preparo localizado, atingindo boas profundidades $(8 \mathrm{a} 15 \mathrm{~cm})$, onde pode ser depositado o adubo.

PORTELLA et al. (1997) não encontraram diferenças significativas no índice de emergência de plantas de milho, em função dos elementos sulcadores e compactadores das semeadoras de precisão testadas, em semeadura direta. Em solos com baixa umidade, aquelas equipadas com sulcador do tipo facão colocaram as sementes em maior profundidade do que as com discos duplos. Nos solos mais úmidos, ocorreu o contrário, indicando problemas de acúmulo de palha na frente dos sulcadores de adubo, afetando a aderência solo-ferramenta.

Considerando que a haste sulcadora fixa, tipo facão, é utilizada em grande escala nas semeadoras-adubadoras de precisão no Brasil, foi elaborado um projeto visando a avaliar a força de tração demandada e o volume de solo mobilizado pela mesma, bem como a patinagem dos rodados motrizes do trator, em função dos estados de consistência do solo, da velocidade de operação do conjunto trator/semeadora-adubadora e da profundidade de atuação da haste sulcadora em área de campo nativo, sob exploração pecuária intensiva há mais de 15 anos.

\section{MATERIAL E MÉTODOS}

O estudo foi realizado na Estação Experimental Agronômica da Universidade Federal do Rio Grande do Sul, município de Eldorado do Sul - RS. O experimento foi instalado em área com Argissolo Vermelho distrófico típico (EMBRAPA, 1999), unidade de mapeamento São Jerônimo (BRASIL, 1973). Esse solo ocupa área de aproximadamente $1.345 \mathrm{~km}^{2}$ e apresenta textura do horizonte superficial franco-argilosa a argilosa com cascalhos. A área do experimento, com declividade entre 0,02 e $0,03 \mathrm{~m} \mathrm{~m}^{-1}$, estava sendo utilizada com pecuária intensiva há 15 anos. POTT (1974) descreveu o campo natural da região como regular, considerando como predominantes as Gramineae Paspalum spp., Aristida spp. e Trachypogon montufari e Setaria geniculata, e referente às Leguminosae destacou-se o Desmodium canum.

Após a dessecação química da vegetação com herbicida de ação total, foi implantada, em semeadura direta, a cultura da soja (Glycine max L.), a qual serviu como cultura-teste para os ensaios realizados. A semeadura ocorreu em três estados de consistência do solo (seco, friável e úmido, ou seja, com teores de água no solo de 0,10; 0,14 e 0,23 $\mathrm{kg} \mathrm{kg}^{-1}$, respectivamente), sendo utilizadas duas profundidades de atuação da haste sulcadora de adubo $(\mathrm{P} 1=6 \mathrm{~cm}$ e P2 $=12 \mathrm{~cm})$ e duas velocidades de operação do conjunto trator/semeadora-adubadora $\left(\mathrm{V} 1=4,5 \mathrm{~km} \mathrm{~h}^{-1} \mathrm{e} \mathrm{V} 2=6,5 \mathrm{~km} \mathrm{~h}^{-1}\right)$.

As dimensões das parcelas experimentais foram de $20 \mathrm{~m}$ de comprimento e 3,5 $\mathrm{m}$ de largura, permitindo a passagem do conjunto trator/semeadora-adubadora e manobras necessárias. Foram instalados três experimentos com delineamento de blocos ao acaso, arranjo fatorial 2 x 2 , com três repetições, um para cada estado de consistência do solo. As comparações de médias foram feitas por meio do teste Tukey, à probabilidade $<0,05$.

Para a adequação da área experimental, instalação e condução do experimento, foram empregados as seguintes máquinas e equipamentos: trator com tração 4x 2 com TDA, potência máxima no motor de $53 \mathrm{~kW}(75 \mathrm{cv})$, equipado com pneus traseiros e dianteiros 18.4x30R1 e 12.4x24R1, respectivamente, parcialmente lastrado, incidindo uma carga aproximada de $2.370 \mathrm{~kg}$ e $1.580 \mathrm{~kg}$ sobre os rodados traseiros e dianteiros, respectivamente, na condição estática; pulverizador de barras, montado, largura útil de 9,5 m, capacidade para $400 \mathrm{~L}$ de calda e semeadora-adubadora de precisão, 
montada, com cinco linhas distanciadas entre si em $0,45 \mathrm{~m}$, com discos de corte lisos para palha com diâmetro de 356 mm (14") instalados à frente de cada linha de semeadura, sulcadores de adubo do tipo facão, sulcadores de sementes tipo discos duplos com $356 \mathrm{~mm}$ (14") de diâmetro e rodas compactadoras de borracha.

Utilizando instrumentação eletrônica, foram adquiridas leituras de deformação da haste por meio de estensômetros nela instalados (FIGURA 1).

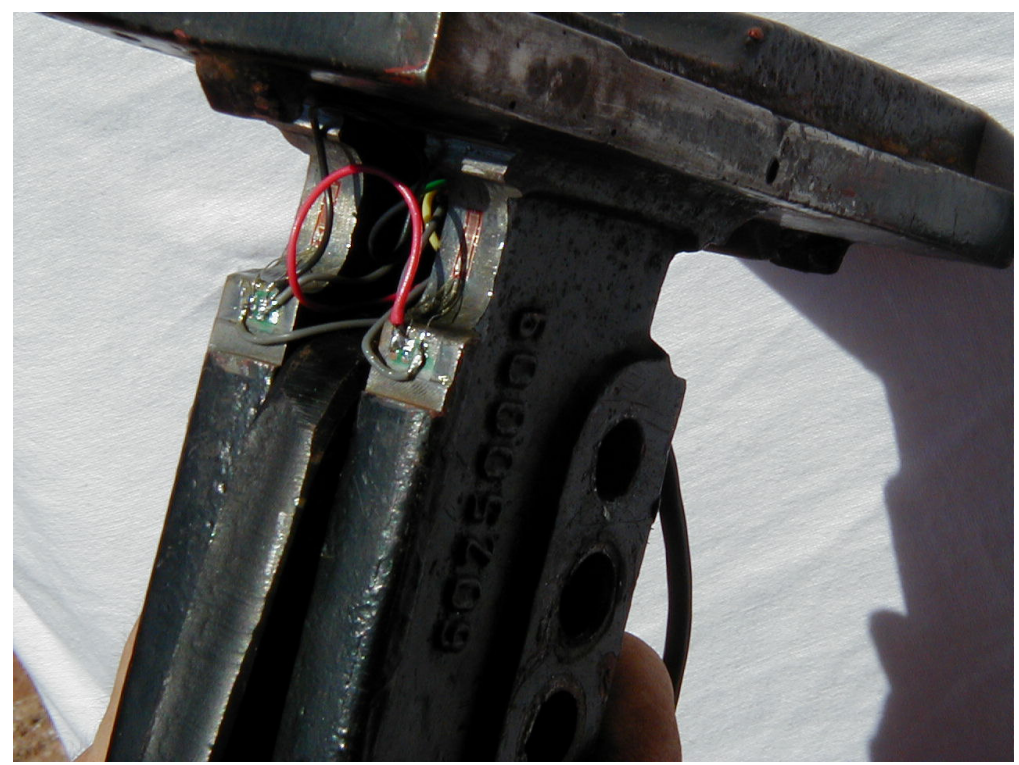

FIGURA 1. Detalhe da instalação dos estensômetros.

Isso permitiu a obtenção da força de tração instantânea da haste sulcadora de adubo instalada na linha central da semeadora-adubadora, numa freqüência de $2 \mathrm{~Hz}$. A haste sulcadora de adubo possuía ângulo de ataque de $18^{\circ}$, altura da haste de $415 \mathrm{~mm}$, espessura de $127 \mathrm{~mm}$ e largura máxima da ponteira de $25,7 \mathrm{~mm}$.

Utilizando sensores de deslocamento, foi efetuado o monitoramento da rotação das rodas traseiras do trator (a TDA não foi acionada) e de roda odométrica localizada lateralmente à haste sulcadora de adubo da semeadora-adubadora. Por meio da diferença entre os dados obtidos para as distâncias percorridas pelas rodas traseiras do trator e pela roda odométrica, foi calculada a patinagem, expressa em porcentagem.

Foram obtidas leituras do perfil de solo mobilizado pelo sulcador de adubo, logo após a passagem do conjunto trator/semeadora-adubadora, em todos os ensaios. Para isto, foram colocadas duas estacas, lateralmente às linhas de semeadura, as quais serviram como referência para as leituras efetuadas com o perfilômetro. $\mathrm{O}$ volume de solo mobilizado foi calculado a partir das leituras de profundidade do sulco $(\mathrm{cm})$ e a largura de trabalho da haste sulcadora de adubo $(\mathrm{cm})$ obtidas com perfilômetro. Foram determinados alguns atributos físicos do Argissolo Vermelho distrófico típico encontrado na área experimental, sendo eles: densidade do solo, densidade dos sólidos, Limites de Atterberg e teor de água no solo, conforme EMBRAPA (1997), e porosidade total, macroporosidade e microporosidade, conforme KIEHL (1979).

Pelos resultados da Tabela 1, observa-se que os atributos do solo avaliados não o caracterizam propriamente como tendo boa estrutura física. Os valores observados são muito semelhantes aos verificados em solos de lavouras que normalmente partem do preparo convencional para a semeadura direta, com a estrutura degradada. No entanto, em função do uso anterior, verificou-se abundante e 
diversificada massa radicular de plantas na camada superficial, semelhante à obtida com culturas de cobertura de inverno, como aveia-preta, por exemplo.

TABELA 1. Atributos físicos do solo Argissolo Vermelho distrófico típico da área experimental.

\begin{tabular}{lccc}
\hline & \multicolumn{3}{c}{ Profundidade $(\mathrm{cm})$} \\
\cline { 2 - 3 } & $0-5$ & $5-10$ & $0-14$ \\
\hline Massa de raízes no solo $\left(\mathrm{Mg} \mathrm{ha}^{-1}\right)$ & - & - & 6,50 \\
Densidade do solo $\left(\mathrm{g} \mathrm{cm}^{-3}\right)$ & 1,70 & 1,67 & - \\
Densidade dos sólidos $\left(\mathrm{g} \mathrm{cm}^{-3}\right)$ & - & - & 2,49 \\
Resistência do solo à penetração $(\mathrm{kPa})^{1}$ & - & - & 1.928 \\
Macroporosidade $\left(\mathrm{cm}^{3} \mathrm{~cm}^{-3}\right)$ & 0,10 & 0,09 & - \\
Microporosidade $\left(\mathrm{cm}^{3} \mathrm{~cm}^{-3}\right)$ & 0,34 & 0,31 & - \\
Porosidade total $\left(\mathrm{cm}^{3} \mathrm{~cm}^{-3}\right)$ & 0,44 & 0,40 & - \\
Limite de liquidez $\left(\mathrm{kg} \mathrm{kg}^{-1}\right)$ & - & - & 0,23 \\
Limite de plasticidade $\left(\mathrm{kg} \mathrm{kg}^{-1}\right)$ & - & - & 0,14 \\
Limite de contração $\left(\mathrm{kg} \mathrm{kg}^{-1}\right)$ & - & - & 0,08 \\
Índice de plasticidade $\left(\mathrm{kg} \mathrm{kg}^{-1}\right)$ & - & - & 0,09 \\
Areia $\left(\mathrm{g} \mathrm{kg}^{-1}\right)$ & 511,4 & 489,2 & - \\
Silte $\left(\mathrm{g} \mathrm{kg}^{-1}\right)$ & 163,0 & 179,1 & - \\
Argila $\left(\mathrm{g} \mathrm{kg}^{-1}\right)$ & 325,6 & 331,7 & - \\
\hline
\end{tabular}

${ }^{1} \mathrm{Ug}=0,13 \mathrm{~kg} \mathrm{~kg}^{-1}$

Os valores de densidade do solo foram elevados, nas duas profundidades analisadas. BAYER (1996), em campo natural, nesse mesmo tipo de solo, encontrou valores semelhantes (entre 1,49 e $1,63 \mathrm{~g} \mathrm{~cm}^{-3}$ ). Observa-se, também, na camada de 5 a $10 \mathrm{~cm}$ de profundidade, valores de macroporosidade menores que $0,10 \mathrm{~cm}^{3} \mathrm{~cm}^{-3}$. Essa porosidade pode restringir o crescimento radicular e o desenvolvimento das plantas (VOMOCIL \& FLOCKER, 1966; GRABLE \& SIEMER, 1968). Uma provável explicação para as elevadas densidades do solo e baixo volume de macroporos na área experimental é que as partículas do solo tendem a se ajustar umas às outras, quando sob a ação de forças a elas aplicadas, no caso, pisoteio animal. Essas tensões podem resultar em elevação da densidade do solo.

BARNES et al. (1971) estudaram as compactações máximas em várias granulometrias de solo, misturando diversas quantidades de areia com o solo. Concluíram que as maiores densidades do solo foram alcançadas com frações de areia de 500 a $850 \mathrm{~g} \mathrm{~kg}^{-1}$. Na área experimental utilizada para este estudo, a distribuição das partículas de solo encontra-se dentro dessa faixa, o que pode significar que o solo da área experimental tenha tendência natural a maior empacotamento das suas partículas.

$\mathrm{Na}$ Tabela 2, constam os valores de teor de água no solo, determinados para a ratificação dos ensaios nos estados de consistência: seco, friável e úmido, apresentados na Tabela 1. Os teores de água no solo, no dia da execução dos ensaios, estavam próximos dos Limites de Atterberg. No ensaio em solo úmido, o teor de água foi ligeiramente superior na profundidade de 0 a $7 \mathrm{~cm}$ do que na de 7 a $14 \mathrm{~cm}$, em função da ocorrência de chuva fraca no dia anterior ao teste. 
TABELA 2. Teor de água no solo em Argissolo Vermelho distrófico típico nos diferentes estados de consistência do solo, no dia da execução dos ensaios.

\begin{tabular}{lccc}
\hline & \multirow{2}{*}{ Estado de Consistência do Solo } & \multicolumn{2}{c}{ Profundidade $(\mathrm{cm})$} \\
\cline { 3 - 4 } & & $0-7$ & $7-14$ \\
\hline Umidade gravimétrica $\left(\mathrm{g} \mathrm{cm}^{-3}\right)$ & \multirow{2}{*}{ Seco } & 0,10 & 0,11 \\
Umidade volumétrica $\left(\mathrm{cm}^{3} \mathrm{~cm}^{-3}\right)$ & & 0,17 & 0,18 \\
\hline Umidade gravimétrica $\left(\mathrm{g} \mathrm{cm}^{-3}\right)$ & \multirow{2}{*}{ Friável } & 0,14 & 0,14 \\
Umidade volumétrica $\left(\mathrm{cm}^{3} \mathrm{~cm}^{-3}\right)$ & & 0,24 & 0,24 \\
\hline Umidade gravimétrica $\left(\mathrm{g} \mathrm{cm}^{-3}\right)$ & \multirow{2}{*}{ Úmido } & 0,23 & 0,21 \\
Umidade volumétrica $\left(\mathrm{cm}^{3} \mathrm{~cm}^{-3}\right)$ & & 0,40 & 0,40 \\
\hline
\end{tabular}

\section{RESULTADOS E DISCUSSÃO}

A instalação do experimento ocorreu em solo sob campo natural, com pastejo intensivo e sem cultivo agrícola nos últimos 15 anos. Na Tabela 3, observa-se que os valores da força de tração medida na haste sulcadora aumentaram significativamente em função do aumento da profundidade de trabalho e, em solo seco, esse aumento foi da ordem de $84 \%$. A força de tração média de $428 \mathrm{~N}$, obtida para a profundidade de atuação de $6 \mathrm{~cm}$, passou a ser de $786 \mathrm{~N}$, quando a profundidade foi de $12 \mathrm{~cm}$. Já com o solo friável, esse aumento foi sensivelmente maior, da ordem de 130\%. A demanda de tração do sulcador, que era em torno de $614 \mathrm{~N}$, passou para cerca de $1.409 \mathrm{~N}$. Pode-se depreender desse fato que o aumento da quantidade de água no solo (de 0,10 para $0,14 \mathrm{~kg} \mathrm{~kg}^{-1}$ ) resultou em aumento das forças de adesão solo-metal, tendo isso sido observado visualmente durante a execução do teste, confirmando dados obtidos por MACHADO (2001). Observando-se os dados da Tabela 3, verifica-se que a maior demanda de tração foi requerida no estado de consistência friável, profundidade de atuação do sulcador de $12 \mathrm{~cm}$ e velocidade de operação de $6,5 \mathrm{~km} \mathrm{~h}^{-1}$, sendo que esse valor não passou de $1.474 \mathrm{~N}$.

TABELA 3. Força de tração $(\mathrm{N})$ demandada pela haste sulcadora de adubo da semeadora-adubadora.

\begin{tabular}{|c|c|c|c|}
\hline & \multicolumn{3}{|c|}{ Solo Seco } \\
\hline & \multicolumn{3}{|c|}{ Velocidade $\left(\mathrm{km} \mathrm{h}^{-1}\right)$} \\
\hline Profundidade $(\mathrm{cm})$ & V1 & $\mathrm{V} 2$ & Média \\
\hline $\mathrm{P} 1$ & 399,0 & 456,1 & $427,5 \mathrm{~b}$ \\
\hline P2 & 769,1 & 801,8 & 785,5 a \\
\hline \multirow[t]{3}{*}{ Média } & $584,0 \mathrm{~A}$ & $628,9 \mathrm{~A}$ & 606,5 \\
\hline & \multicolumn{3}{|c|}{ Solo Friável } \\
\hline & \multicolumn{3}{|c|}{ Velocidade $\left(\mathrm{km} \mathrm{h}^{-1}\right)$} \\
\hline Profundidade $(\mathrm{cm})$ & V1 & $\mathrm{V} 2$ & Média \\
\hline $\mathrm{P} 1$ & $612,1 \mathrm{Ab}$ & $615,4 \mathrm{Ab}$ & 613,7 \\
\hline P2 & $1.343,6 \mathrm{Ba}$ & $1.474,2 \mathrm{Aa}$ & $1.408,9$ \\
\hline \multirow[t]{3}{*}{ Média } & 977,8 & $1.044,8$ & $1.011,3$ \\
\hline & \multicolumn{3}{|c|}{ Solo Úmido } \\
\hline & \multicolumn{3}{|c|}{ Velocidade $\left(\mathrm{km} \mathrm{h}^{-1}\right)$} \\
\hline Profundidade $(\mathrm{cm})$ & V1 & $\mathrm{V} 2$ & Média \\
\hline $\mathrm{P} 1$ & 670,8 & 654,6 & $662,7 \mathrm{~b}$ \\
\hline P2 & $1.154,9$ & $1.158,8$ & $1.156,9 \mathrm{a}$ \\
\hline Média & $912,8 \mathrm{~A}$ & 906,7A & 909,8 \\
\hline
\end{tabular}

Médias seguidas de mesma letra minúscula nas colunas e maiúsculas nas linhas não diferem entre si, pelo teste de Tukey (P $<0,05)$. 
Quando o solo passa do estado de consistência friável a úmido, ou seja, do teor de água de 0,14 para $0,22 \mathrm{~kg} \mathrm{~kg}^{-1}$, a força que a haste necessitou para rompê-lo a $6 \mathrm{~cm}$ de profundidade foi de $663 \mathrm{~N}$, enquanto a $12 \mathrm{~cm}$, essa foi de $1.157 \mathrm{~N}$, significando aumento de $75 \%$.

Comparando-se os valores de força de tração medidos na haste sulcadora operada em solo friável e úmido, verifica-se que esses foram semelhantes a $6 \mathrm{~cm}$ de profundidade. Porém, a $12 \mathrm{~cm}$, foram menores na condição úmida. Isso pode ser devido a um efeito de lubrificação pela água ou da influência da mesma na diminuição das tensões entre as partículas sólidas de solo.

Em solo seco ou úmido, o aumento da velocidade de trabalho de 4,5 para $6,5 \mathrm{~km} \mathrm{~h}^{-1}$ não alterou significativamente a força de tração. Já no solo friável, houve aumento significativo de $7 \%$ no esforço de tração (média das profundidades de atuação da haste). Entretanto, esse efeito foi verificado somente quando o sulcador atuou à profundidade de $12 \mathrm{~cm}$, ou seja, a força de tração só aumentou significativamente quando o sulcador atuou mais profundamente. Isso pode ser devido à alteração no formato da falha do solo que de falha não-confinada no rompimento da camada superficial $(0-6 \mathrm{~cm})$, passou a ser de falha confinada na camada imediatamente inferior $(6-12 \mathrm{~cm})$.

Para confirmar a alteração do modo de falha e, eventualmente, identificar a profundidade crítica, há necessidade de testes mais detalhados, os quais não foram executados no presente trabalho.

SIQUEIRA et al. (2001), utilizando 13 diferentes modelos de sulcadores tipo facão em semeadoras-adubadoras de precisão, obtiveram valores de força de tração medida na haste entre $1.376 \mathrm{~N}$ e $2.200 \mathrm{~N}$, numa velocidade média de deslocamento de $5,5 \mathrm{~km} \mathrm{~h}^{-1}$. A profundidade de atuação dos sulcadores testados variou entre 11,7 a $13,3 \mathrm{~cm}$. No entanto, os testes foram efetuados em solos já utilizados para agricultura e com textura muito argilosa, diferente do empregado no presente experimento.

$\mathrm{Na}$ Tabela 4, observa-se que a relação entre a força de tração medida na haste sulcadora de adubo e a área transversal de solo mobilizado pela mesma, ou seja, a força de tração específica $\left(\mathrm{N} \mathrm{cm}^{-2}\right)$, não foi influenciada pelo fator velocidade de deslocamento do conjunto trator/semeadoraadubadora em nenhum dos teores de água do solo ensaiados. Porém, houve diferença significativa em função do fator profundidade de atuação do sulcador nos ensaios conduzidos em solo seco e friável, com maiores valores para P2 $(12 \mathrm{~cm})$, não havendo significância quando operado em solo úmido. Os dados podem ser explicados pelo fato de que, em solo seco e friável, ao regular a profundidade do sulcador de $6 \mathrm{~cm}$ para $12 \mathrm{~cm}$, houve também aumento na área de solo mobilizado, juntamente com a força de tração. Na condição de solo úmido, a força de tração também aumentou em função da profundidade, mas a área de solo mobilizado não aumentou na mesma proporção.

A principal função de um sulcador fixo, no sistema de semeadura direta, deve ser a descompactação e/ou mobilização do solo em subsuperfície, em profundidade e extensão estipuladas tecnicamente. A condição de solo e as necessidades das culturas devem definir as regulagens a serem realizadas no disco de corte (profundidade de trabalho) e no próprio sulcador (profundidade de trabalho, ângulo de ataque, tipo e tamanho da ponteira e da haste do mesmo).

No entanto, o trabalho efetuado pelo sulcador deve causar o mínimo distúrbio possível na superfície do solo, pois afeta a cobertura por resíduos e propicia condições para a emergência de plantas daninhas às culturas exploradas economicamente.

Desse modo, observando-se os valores apresentados na Tabela 5, verifica-se que o maior volume de solo mobilizado pela haste sulcadora foi obtido em solo friável na maior velocidade e maior profundidade testadas $\left(135,9 \mathrm{~m}^{3} \mathrm{ha}^{-1}\right)$. Em todos os ensaios, os maiores valores de volume de solo mobilizado foram obtidos quando a profundidade de operação da haste sulcadora foi de $12 \mathrm{~cm}$, com valores de 110,0;128,8 e 125,5 $\mathrm{m}^{3} \mathrm{ha}^{-1}$, respectivamente, para o solo em consistência seco, friável e úmido. No estado de consistência úmido, não houve diferença significativa em relação ao fator 
velocidade de operação do conjunto trator/semeadora-adubadora. Porém, no estado de consistência friável, a velocidade de operação teve influência significativa no volume de solo mobilizado com sulcador operando a $12 \mathrm{~cm}$ de profundidade. $\mathrm{O}$ volume de solo mobilizado aumentou $12 \%$ quando a velocidade de semeadura passou de $4,5 \mathrm{~km} \mathrm{~h}^{-1}$ para $6,5 \mathrm{~km} \mathrm{~h}^{-1}$.

TABELA 4. Força de tração específica $\left(\mathrm{N} \mathrm{cm}^{-2}\right)$ demandada pela haste sulcadora de adubo da semeadora-adubadora.

\begin{tabular}{|c|c|c|c|}
\hline & \multicolumn{3}{|c|}{ Solo Seco } \\
\hline & \multicolumn{3}{|c|}{ Velocidade $\left(\mathrm{km} \mathrm{h}^{-1}\right)$} \\
\hline Profundidade $(\mathrm{cm})$ & V1 & $\mathrm{V} 2$ & Média \\
\hline $\mathrm{P} 1$ & 9,73 & 10,20 & $9,97 \mathrm{~b}$ \\
\hline P2 & 15,17 & 16,70 & $15,93 \mathrm{a}$ \\
\hline \multirow[t]{3}{*}{ Média } & $12,45 \mathrm{~A}$ & $13,45 \mathrm{~A}$ & 12,95 \\
\hline & \multicolumn{3}{|c|}{ Solo Friável } \\
\hline & \multicolumn{3}{|c|}{ Velocidade $\left(\mathrm{km} \mathrm{h}^{-1}\right)$} \\
\hline Profundidade $(\mathrm{cm})$ & V1 & $\mathrm{V} 2$ & Média \\
\hline $\mathrm{P} 1$ & 19,17 & 22,27 & $20,72 b$ \\
\hline $\mathrm{P} 2$ & 24,67 & 24,20 & $24,43 \mathrm{a}$ \\
\hline \multirow[t]{3}{*}{ Média } & $21,92 \mathrm{~A}$ & $23,23 \mathrm{~A}$ & 22,57 \\
\hline & \multicolumn{3}{|c|}{ Solo Úmido } \\
\hline & \multicolumn{3}{|c|}{ Velocidade $\left(\mathrm{km} \mathrm{h}^{-1}\right)$} \\
\hline Profundidade $(\mathrm{cm})$ & V1 & $\mathrm{V} 2$ & Média \\
\hline $\mathrm{P} 1$ & 19,67 & 21,70 & $20,67 \mathrm{a}$ \\
\hline $\mathrm{P} 2$ & 21,43 & 19,90 & $20,68 \mathrm{a}$ \\
\hline Média & $20,55 \mathrm{~A}$ & $20,80 \mathrm{~A}$ & 20,67 \\
\hline
\end{tabular}

Médias seguidas de mesma letra minúscula nas colunas e maiúsculas nas linhas não diferem entre si, pelo teste de Tukey $(\mathrm{P}<0,05)$

TABELA 5. Volume de solo mobilizado $\left(\mathrm{m}^{3} \mathrm{ha}^{-1}\right)$ pela haste sulcadora de adubo de semeadoraadubadora.

\begin{tabular}{cccc}
\hline & \multicolumn{4}{c}{ Solo Seco } \\
\cline { 2 - 4 } & $\mathrm{V} 1$ & Velocidade $\left(\mathrm{km} \mathrm{h}^{-1}\right)$ & Média \\
\hline Profundidade $(\mathrm{cm})$ & 91,3 & 99,9 & $95,6 \mathrm{~b}$ \\
P1 & 112,8 & 107,2 & $110,0 \mathrm{a}$ \\
P2 & $102,0 \mathrm{~B}$ & $103,5 \mathrm{~A}$ & 102,8 \\
\hline Média & \multicolumn{4}{c}{ Solo Friável } \\
\cline { 2 - 4 } & $\mathrm{V} 1$ & Velocidade $\left(\mathrm{km} \mathrm{h}^{-1}\right)$ & Média \\
\hline Profundidade $(\mathrm{cm})$ & $72,2 \mathrm{Ab}$ & 66,8 \\
P1 & $121,8 \mathrm{Ba}$ & $61,5 \mathrm{Ab}$ & 128,8 \\
P2 & 97,0 & 135,9 Aa & 97,8 \\
Média & \multicolumn{4}{c}{98,7} \\
\hline Profundidade $(\mathrm{cm})$ & $\mathrm{V} 1$ & Solo Úmido & Melocidade $\left(\mathrm{km} \mathrm{h}^{-1}\right)$ \\
\hline P1 & 76,9 & V2 & $72,1 \mathrm{~b}$ \\
P2 & 121,3 & 67,3 & 98,8 \\
\hline
\end{tabular}

Médias seguidas de mesma letra minúscula nas colunas e maiúsculas nas linhas não diferem entre si, pelo teste de Tukey $(\mathrm{P}<0,05)$ 
A patinagem das rodas motrizes do trator variou com os diferentes teores de água do solo, conforme pode ser verificado na Tabela 6 . Na condição de solo seco e friável, os valores mais elevados de patinagem foram obtidos na maior profundidade de atuação do sulcador e na maior velocidade de deslocamento testados. Porém, na condição de solo úmido, não ocorreu aumento significativo da patinagem em função do aumento da velocidade de deslocamento de $4,5 \mathrm{~km} \mathrm{~h}^{-1}$ para $6,5 \mathrm{~km} \mathrm{~h}^{-1}$.

Os valores de patinagem obtidos indicam a necessidade de acionamento da TDA do trator quando a operação de semeadura foi realizada à profundidade de $12 \mathrm{~cm}$, no tipo de solo e de semeadora especificados, independentemente do teor de água do solo.

TABELA 6. Patinagem dos rodados do trator (\%) na operação de semeadura.

\begin{tabular}{|c|c|c|c|}
\hline \multicolumn{4}{|c|}{ Solo Seco } \\
\hline & \multicolumn{3}{|c|}{ Velocidade $\left(\mathrm{km} \mathrm{h}^{-1}\right)$} \\
\hline Profundidade $(\mathrm{cm})$ & V1 & $\mathrm{V} 2$ & Média \\
\hline $\mathrm{P} 1$ & 4,1 & 10,8 & $7,4 \mathrm{~b}$ \\
\hline P2 & 16,9 & 20,4 & $18,7 \mathrm{a}$ \\
\hline \multirow[t]{3}{*}{ Média } & $10,5 \mathrm{~B}$ & $15,6 \mathrm{~A}$ & 13,0 \\
\hline & \multicolumn{3}{|c|}{ Solo Friável } \\
\hline & \multicolumn{3}{|c|}{ Velocidade $\left(\mathrm{km} \mathrm{h}^{-1}\right)$} \\
\hline Profundidade $(\mathrm{cm})$ & V1 & $\mathrm{V} 2$ & Média \\
\hline $\mathrm{P} 1$ & 5,9 & 10,9 & $8,4 \mathrm{~b}$ \\
\hline P2 & 15,7 & 19,1 & $17,4 \mathrm{a}$ \\
\hline \multirow[t]{3}{*}{ Média } & $10,8 \mathrm{~B}$ & $15,0 \mathrm{~A}$ & 12,9 \\
\hline & \multicolumn{3}{|c|}{ Solo Úmido } \\
\hline & \multicolumn{3}{|c|}{ Velocidade $\left(\mathrm{km} \mathrm{h}^{-1}\right)$} \\
\hline Profundidade $(\mathrm{cm})$ & V1 & $\mathrm{V} 2$ & Média \\
\hline $\mathrm{P} 1$ & 8,0 & 10,3 & $9,2 \mathrm{~b}$ \\
\hline $\mathrm{P} 2$ & 18,8 & 18,4 & $18,6 \mathrm{a}$ \\
\hline Média & $13,4 \mathrm{~A}$ & $14,4 \mathrm{~A}$ & 13,9 \\
\hline
\end{tabular}

\section{CONCLUSÕES}

A força de tração, medida na haste sulcadora de adubo da semeadora-adubadora, aumentou entre $70 \%$ e $130 \%$ em função do aumento da profundidade de trabalho, de $6 \mathrm{~cm}$ para $12 \mathrm{~cm}$, dependendo do teor de água do solo. $\mathrm{O}$ aumento da velocidade de deslocamento resultou em maiores valores de esforço de tração apenas na condição de friabilidade e com sulcador operando a $12 \mathrm{~cm}$ de profundidade.

A força de tração específica requerida pelo sulcador não foi influenciada pela velocidade de deslocamento do conjunto trator/semeadora-adubadora em nenhum dos teores de água no solo, sendo maior na profundidade de $12 \mathrm{~cm}$ em solo seco e friável, não havendo diferença com solo úmido.

A profundidade de atuação dos sulcadores teve influência significativa sobre a patinagem dos rodados em todos os estados de consistência do solo. Quando as hastes sulcadoras de adubo foram reguladas para atuação a $12 \mathrm{~cm}$, os limites aceitáveis de patinagem para o trator, sem utilização da TDA, foram ultrapassados. A velocidade de deslocamento do conjunto trator/semeadora-adubadora influenciou na patinagem na condição de solo seco e friável, com maiores valores na maior velocidade testada. 


\section{REFERÊNCIAS}

BARNES K.X.; CARLETON, W.M.; TAYLOR, H.M; THROCKMORTON, R.T.; VANDEN BERG, G.E. Compaction of agricultural soils. St. Joseph: ASAE, 1971. 471 p.

BAYER, C. Dinâmica da matéria orgânica em sistemas de manejo de solos. 1996. 240 f. Tese (Doutorado em Ciência do Solo) - Faculdade de Agronomia, Universidade Federal do Rio Grande do Sul, Porto Alegre, 1996.

BERTOL, O.J.; AMADO, T.J.C.; SCHLOSSER, J.F.; REINERT, D.J. Desempenho de mecanismos sulcadores de semeadura sob condição de preparo reduzido do solo. Revista Brasileira de Ciência do Solo, Campinas, v.21, n.2, p.257-62, 1997.

BOENI, M. Comportamento mecânico de solos escarificados em função do teor de água e pressão de inflação dos pneus do trator. 2000. 99 f. Dissertação (Mestrado em Ciência do Solo) - Faculdade de Agronomia, Universidade Federal do Rio Grande do Sul, Porto Alegre, 2000.

BRASIL. Ministério da Agricultura. Departamento Nacional de Pesquisa Agropecuária. Divisão de Pesquisa Pedológica. Levantamento de reconhecimento dos solos do Estado do Rio Grande do Sul. Recife: IPEAS, 1973. 431 p. (Boletim técnico, 30)

CASÃO JÚNIOR, R.; ARAÚJO, A.G.; RALISH, R.; SILVA, A.L.; LADEIRA, A.S.; SILVA, J.C.; MACHADO, P.; ROSSETO, R. Avaliação do desempenho da semeadora-adubadora Magnum 2850 PD no basalto paranaense. Circular Instituto Agronômico do Paraná, Londrina, n.105, p.1-47, 1998.

CASÃO JÚNIOR, R.; ARAÚJO, A.G.; RALISH, R. Desempenho da semeadora-adubadora Magnum 2850 em plantio direto no basalto paranaense. Pesquisa Agropecuária Brasileira, Brasília, v.35, n.3, p.523-32, 2000.

CEPIK, C.T.C. Análise de desempenho de uma haste sulcadora de semeadora-adubadora, em diferentes teores de água no solo, velocidades e profundidades de trabalho. 2002. 62 f. Dissertação (Mestrado em Ciência do Solo) - Faculdade de Agronomia, Universidade Federal do Rio Grande do Sul, Porto Alegre, 2002.

EMPRESA BRASILEIRA DE PESQUISA AGROPECUÁRIA. Manual de métodos de análise de solo. 2.ed. Rio de Janeiro, 1997. 247 p.

EMPRESA BRASILEIRA DE PESQUISA AGROPECUÁRIA. Sistema brasileiro de classificação de solos. Rio de Janeiro, 1999. $412 \mathrm{p}$.

GRABLE, A.R.; SIEMER, E.G. Effects of bulk density, aggregate size, and soil water suction on oxygen diffusion, redox potential and elongation of corns roots. Soil Science Society of America Proceedings, Madison, v.32, n.1, p.180-6, 1968.

KIEHL, E.J. Porosidade. In: Manual de edafologia. São Paulo: Ceres, 1979. p.96-109.

MACHADO, A.L.T. Esforço de tração para ferramentas de hastes com ponteiras estreitas em dois solos do Rio Grande do Sul. 2001. 175 f. Tese (Doutorado em Ciência do Solo) - Faculdade de Agronomia, Universidade Federal do Rio Grande do Sul, Porto Alegre, 2001.

PORTELLA, J.A.; SATTLER, A.; FAGANELLO, A. Índice de emergência de plântulas de soja e de milho em semeadura direta no Sul do Brasil. Engenharia Agrícola, Jaboticabal, v.17, n.2, p.71-8, dez. 1997.

POTT, A. Levantamento Ecológico da vegetação de um campo natural sob três condições: pastejado, excluído e melhorado. 1974. 223 f. Dissertação (Mestrado em Plantas Forrageiras) - Faculdade de Agronomia, Universidade Federal do Rio Grande do Sul, Porto Alegre, 1974. 
SILVA, V.R. Compressibilidade de um podzólico e um latossolo em função do estado inicial de compactação e saturação em água. 1999. 98 f. Dissertação (Mestrado em Biodinâmica dos Solos) Faculdade de Agronomia, Universidade Federal de Santa Maria, Santa Maria, 1999.

SIQUEIRA, R.; CASÃO JÚNIOR R.; RALISCH, R.; ARAÚJO, A.G. Variabilidade da demanda energética de hastes sulcadoras de semeadoras-adubadoras diretas. In: CONGRESSO BRASILEIRO DE ENGENHARIA AGRÍCOLA, 30., 2001, Foz do Iguaçu. Anais... Foz do Iguaçu: Sociedade Brasileira de Engenharia Agrícola, 2001. 1 CD-ROM.

SOANE, B.D.; OUWERKERK, C. Van. Soil compaction in crop production. Amsterdam: Elsevier, 1994. $662 \mathrm{p}$.

VOMOCIL, J.A.; FLOCKER, W.J. Effect of soil compaction on storage and movement of soil air and water. Transaction of the ASAE, St. Joseph, v.4, n.1, p.242-6, 1966. 